\title{
Rates of photosynthesis in leaves of wheat and barley varieties
}

\section{G. Dantuma}

Institute for Biological and Chemical Research on Field Crops and Herbage (IBS), Wageningen, the Netherlands

Accepted: 16 February 1973

\section{Summary}

Differences in rates of photosynthesis in leaves of a number of spring wheat and spring barley varieties of very different origin could be established, the maximum differences between genotypes being $22 \%$ and $20 \%$, respectively. The range of mean values in spring wheat was 325-414 $\mu \mathrm{g} \mathrm{CO}_{2} \mathrm{~cm}^{-2} \mathrm{~h}^{-1}$ and in spring barley 284-366 $\mu \mathrm{g} \mathrm{CO}_{2}$ $\mathrm{cm}^{-2} \mathrm{~h}^{-1}$. In the first experiments, the range of variability within genotypes caused many difficulties with the measurements. These were partly solved by improving the conditions under which the plants were grown.

Maximum rates of photosynthesis were found in leaves that had attained their ultimate area; these rates decrease gradually with the ageing of the leaves. A regulation of photosynthesis by the demand for assimilates could not be established, the age of the leaf being the most important character for the photosynthetic capacity. Low nitrogen supply and, because of this, low protein contents in the leaves have a reducing effect on rates of photosynthesis. Within leaves of the same age, rate of photosynthesis is correlated with the protein content; this is not the case between leaves of different ages.

\section{Introduction}

Variation in photosynthetic efficiency between and within species of wheat and barley has been widely demonstrated in recent years. Mostly these variations were found by gas-exchange techniques, mainly $\mathrm{CO}_{2}$ uptake by infrared analysis. Sometimes such differences were found by estimating the net assimilation rate (NAR) (e.g. Lupton, 1961). However, the estimation of NAR has several disadvantages. First it is time-consuming and therefore rather unsuitable for comparing a number of varieties or selections. Moreover, in measuring the photosynthetic area the complicating factors of mutual shading and loss in photosynthetic activity with ageing may occur. These factors are difficult to measure and may show varietal differences because of which crop photosynthesis probably is not linearly related to the leaf area duration (LAD).

For these reasons a direct method such as the gas-exchange technique was preferred to an indirect method. As cereal crops are composed almost entirely of carbohydrates and water, the determining physiological factors are mainly differences in:

1. the efficiency of light energy in the conversion of $\mathrm{CO}_{2}$ into carbohydrates;

2. distribution of dry matter in the plant between the most and the least economically valuable parts.

An improvement in one or both of the mentioned above factors could be of considerable interest to the breeder. 


\section{PHOTOSYNTHESIS IN LEAVES OF WHEAT AND BARLEY VARIETIES}

The main objective of this study was to obtain more information on varietal differences in rates of photosynthesis. As it has been well established that grain production largely depends on dry matter production after flowering and that the flag leaf is in this respect by far the most important leaf in a closed canopy, the investigations were limited mainly to this leaf of the plant.

As is turned out in some preliminary experiments, is was difficult to obtain results with reasonably low standard deviations. So probable factors for these deviations had to be studied first, to obtain experimental results without too many repetitions and of reasonable reproducibility. Furthermore, some experiments had to be devoted to the influence of age of the leaves on their rates of photosynthesis, because age differences of some days cannot be avoided when comparing different varieties. In connection with these experiments on ageing, the influence of the demand for assimilates by the ears on the rates of photosynthesis of the leaves was studied, as there is some disagreement in the literature about this relation.

\section{Materials and methods}

All the experiments were carried out on leaves of intact plants. To this purpose single plants were raised in a growth chamber at 15 or $20^{\circ} \mathrm{C}, 17 \mathrm{~h}$ day-light and a light intensity of about $0.1 \mathrm{cal} \mathrm{cm}^{-2} \mathrm{~min}^{-1}$. At first the plants were placed on one-litre black plastic pots filled with nutrient solution. Later on containers of 9 litres capacity were used each with three plants; the containers were placed on a turntable, to ensure the greatest possible uniformity. Louwerse \& van Oorschot (1969) have described the equipment used at our Institute for estimating gas exchange. I used assimilation chambers of 'sandwich' type (Stoy, 1965) but with $250 \mathrm{~mm} \times 120 \mathrm{~mm} \times 26 \mathrm{~mm}$ inside dimensions. The central $6 \mathrm{~mm}$ of the height of the 'sandwich' was of two layers of foam rubber, which gave an almost airtight seal and prevented damage to leaves. Nylon threads were stretched tight between the two layers and along the length of the chamber. By weaving the leaves carefully through some of the threads, curling or twisting of the leaves could almost be prevented. In this way there is not much difference between the surface that was fully exposed to the light and the measured leaf area.

Growing stages of the plants are given in the Feekes scale, in the old as well as in the new classification (the latter in brackets).

\section{Rates of photosynthesis of wheat leaves in relation to age}

Experiment 1. Plants of the spring wheat selection Artois $\times$ Mexico 43 were raised for $7,8,9$ and 10 weeks at $15^{\circ} \mathrm{C}$ and had attained the stages $8+, 9 / 10,10.1$ and 10.5.1, respectively, or according to the new Feekes scale the stages 3.6, 4.3, 5.2 and 6.1.

The rates of photosynthesis determined at a light intensity of about $0.45 \mathrm{cal} \mathrm{cm}^{-2}$ $\min ^{-1}$ are given in Table 1.

Experiment 2. Plants of the spring wheat variety Sonora $64^{1}$ were grown at $15^{\circ} \mathrm{C}$. The rates of photosynthesis were determined of the last three leaves when just full-grown

1 As this variety appeared not to be pure, a selection was made of it, which has been used in the experiments. 
Table 1. Experiment 1. Rates of photosynthesis in wheat selection Artois $\times$ Mexico 43 . Values printed in the same type (roman or italic) are not significantly different.

\begin{tabular}{|c|c|c|c|c|}
\hline \multirow{4}{*}{$\begin{array}{l}\text { Flag leaf } \\
\text { Penultimate leaf }\end{array}$} & \multicolumn{4}{|c|}{ Rate of photosynthesis $\left(\mu \mathrm{g} \mathrm{CO} \mathrm{cm}^{-2} \mathrm{~h}^{-1}\right)$ at stage } \\
\hline & $8+$ & $9 / 10$ & 10.1 & 10.5 .1 \\
\hline & - & 367 & 379 & 383 \\
\hline & 369 & 365 & 327 & 329 \\
\hline
\end{tabular}

Table 2. Experiment 2. Rates of photosynthesis in spring wheat variety Sonora 64. Values printed in the same type (roman or italic) are not significantly different.

\begin{tabular}{lll}
\hline & \multicolumn{2}{l}{ Rate of photosynthesis $\left(\mu \mathrm{g} \mathrm{CO} \mathrm{cm}^{-2} \mathrm{~h}-1\right)$ at stage } \\
\cline { 2 - 3 } & leaf full-grown & 10.5 .1 \\
Flag leaf & 374 & 382 \\
Penultimate leaf & 368 & 344 \\
3rd leaf from top & 379 & 302 \\
\hline
\end{tabular}

and also from plants at stage 10.5.1 (6.1), the beginning of flowering, at a light intensity of about $0.45 \mathrm{cal} \mathrm{cm}^{-} 2 \mathrm{~min}^{-1}$ (Table 2).

Experiment 3. Plants of Sonora 64 were grown at $20^{\circ} \mathrm{C}$ and the rates of photosynthesis of the last three leaves were again determined, but now at the stages $10,10.5 .3$ and 11.1 (or, in the new scale, 4.5, 6.5 and 7.1; 7.1 = early milky ripe) (Table 3).

Although in Experiment 1 the flag leaf in stage $9 / 10$ had a somewhat lower rate of photosynthesis than in the two older stages these differences were not significant. Flag leaves at a younger stage could not be included, because of the dimensions of the assimilation chambers. After attaining its ultimate area, the rate of photosynthesis of a leaf retained its maximum value for a certain time, after which it decreased gradually, as can be seen from the results of the three experiments. There were considerable decreases in these rates of the older leaves in Experiment 3, although apparently their colour, for instance, did not differ from that of the younger ones. Plants grown at $20 \mathrm{C}^{\circ}$ gave much lower rates of photosynthesis (Table 3) than those grown at $15^{\circ} \mathrm{C}$ (Table 2).

Table 3. Experiment 3. Rates of photosynthesis in spring wheat variety Sonora 64. Values printed in the same type (roman, italic or bold) are not significantly different.

\begin{tabular}{lccc}
\hline & \multicolumn{3}{l}{ Rate of photosynthesis $\left(\mu \mathrm{g} \mathrm{CO}_{2} \mathrm{~cm}^{-2} \mathrm{~h}^{-1}\right)$} \\
\cline { 2 - 4 } & 10 & 10.5 .3 & 11.1 \\
Flag leaf & $\mathbf{3 1 0}$ & $\mathbf{3 2 2}$ & 264 \\
Penultimate leaf & $\mathbf{3 0 3}$ & 254 & 174 \\
3rd leaf from top & 234 & 236 & 126 \\
\hline
\end{tabular}




\section{Photosynthesis of wheat leaves in relation to nitrogen supply}

In the attempts to obtain uniformer results, a few experiments were done to see how far the results can be influenced by the nitrogen supply to the plant. Plants of Sonora 64 were raised at $20^{\circ} \mathrm{C}$ in a growth chamber to stage $10.5 .1-10.5 .3(6.1-6.3)$. In the nutrient solution of half the plants the nitrogen supply was decreased to $1 \%$ of the normal concentration 10 days before the experiments. The results are given in Table 4; each treatment comprised 12 plants. Light intensity was about $0.45 \mathrm{cal} \mathrm{cm}^{-2} \mathrm{~min}^{-1}$ ).

There was considerable variability in the results, which increased with ageing of leaves and with a low nitrogen supply. Furthermore is could be established that there is a certain correlation between protein content of the leaves and rates of photosynthesis. Since the results suggested that with ageing of leaves and a decrease in protein content variability increases, this experiment was repeated with plants of the same variety, grown under the same conditions, but at an older stage, viz 11.1 (7.1; kernels early milky ripe). Results are given in Table 5.

Contrary to the foregoing results the variability in this experiment was hardly affected by age or nitrogen supply. Again a correlation between protein content and rate of photosynthesis could be observed, but this only holds for leaves of the same age and not between leaves of different ages.

Table 4. Rates of photosynthesis $\left(\mu \mathrm{g} \mathrm{CO}_{2} \mathrm{~cm}^{-2} \mathrm{~h}^{-1}\right)$ in leaves of spring wheat variety Sonora 64 in relation to nitrogen supply. Stage 10.5.1-10.5.3 (6.1-6.3).

\begin{tabular}{lllllll}
\hline & $\begin{array}{l}\mathrm{CO}_{2} \\
\text { uptake }\end{array}$ & Range & $\begin{array}{l}\% \mathrm{~N} \times \\
6.25 *\end{array}$ & Range & $\% \mathrm{NO}_{3} *$ & Range \\
& & & & & & \\
Flag leaf, normal N & 350 & $329-369$ & 32.9 & $30.6-34.3$ & 1.12 & $0.76-1.62$ \\
Flag leaf, low N & 319 & $250-341$ & 30.8 & $28.7-33.9$ & 0.15 & $0.10-0.22$ \\
Penultimate leaf, normal N & 287 & $248-342$ & 30.1 & $24.9-33.4$ & 1.19 & $0.75-1.62$ \\
Penultimate leaf, low N & 188 & $127-300$ & 26.3 & $22.8-30.2$ & 0.20 & $0.11-0.33$ \\
\hline
\end{tabular}

* In dry matter of the leaves.

Table 5. Rates of photosynthesis $\left(\mu \mathrm{g} \mathrm{CO} \mathrm{cm}^{-2} \mathrm{~h}^{-1}\right)$ in leaves of spring wheat variety Sonora 64 in relation to nitrogen supply. Stage 11.1 (7.1; kernels early milky ripe).

\begin{tabular}{lllllll}
\hline & $\begin{array}{l}\mathrm{CO}_{2} \\
\text { uptake }\end{array}$ & Range & $\begin{array}{l}\% \mathrm{~N} \times \\
6.25^{*}\end{array}$ & Range & $\% \mathrm{NO}_{3}{ }^{*}$ & Range \\
& & & & & & \\
Flag leaf, normal N & 297 & $275-321$ & 34.9 & $32.1-36.4$ & 0.99 & $0.11-1.58$ \\
Flag leaf, low N & 277 & $254-301$ & 30.5 & $27.2-31.7$ & 0.21 & $0.07-0.42$ \\
$\begin{array}{l}\text { Penultimate leaf, normal N } \\
\text { Penultimate leaf, low N }\end{array}$ & 261 & $242-288$ & 35.2 & $33.6-36.7$ & 2.58 & $0.84-3.90$ \\
& 237 & $213-254$ & 29.4 & $28.1-30.8$ & 0.56 & $0.25-1.21$ \\
\hline
\end{tabular}

* In dry matter of the leaves.

\section{Effect of ear removal on rates of photosynthesis in wheat}

Disagreement in literature about the effect of the demand for assimilates on the rate of photosynthesis was a motive for the following experiment in which it was investigated to what extent this rate was affected by: 
Table 6. Reduction (\%) in rates of photosynthesis after 16 hours at full light intensity as compared with rates after 2 hours. Spring wheat variety Sonora 64 , stage $10.5 .3(6.3)$.

\begin{tabular}{|c|c|c|c|}
\hline \multicolumn{2}{|c|}{ Control $(360) *$} & \multicolumn{2}{|c|}{ Ears removed $(373) *$} \\
\hline plant No & reduction $(\%)$ & plant No & reduction $(\%)$ \\
\hline 1 & 16 & 3 & 17 \\
\hline 2 & 13 & 4 & 3 \\
\hline 5 & 2 & 7 & 55 \\
\hline 6 & 12 & 8 & 72 \\
\hline 9 & 34 & 11 & 49 \\
\hline 10 & 11 & 12 & 8 \\
\hline
\end{tabular}

* Figures in parentheses are average maximum rate of photosynthesis $\left(\mu \mathrm{g} \mathrm{CO}_{2} \mathrm{~cm}^{-2} \mathrm{~h}^{-1}\right)$ after 2 hours.

a: leaving the plants for a longer time at the highest light intensity (about $0.45 \mathrm{cal}$ $\left.\mathrm{cm}^{-2} \min ^{-1}\right)$

b: removal of the ears from some of the plants.

The spring wheat variety Sonora 64 was used for this experiment, again at two different stages, flowering half way, 10.5 .3 (6.3) and early milky ripe 11.1 (7.1). As four leaf chambers were available, four plants were treated each day. The treatment was always begun at the sime time in the morning. At 17.00 the ears and half of the visible part of the peduncle were removed from two plants and the four plants were kept at full light intensity until the next morning. The results of the treatment groups, 4 plants per day, i.e. 2 control plants and 2 plants from which the ears were removed, are presented in Tables 6 and 7.

An increase in rate of photosynthesis in the seed-filling stage was not observed. On the

Table 7. Reduction (\%) in rates of photosynthesis in leaves of spring wheat variety Sonora 64 after 16 hours as compared with rates after 2 hours. Stage 11.1 (7.1).

\begin{tabular}{|c|c|c|c|}
\hline \multicolumn{2}{|l|}{ Control } & \multicolumn{2}{|c|}{ Ears removed } \\
\hline plant No & reduction $(\%)$ & plant No & reduction $(\%)$ \\
\hline \multicolumn{4}{|c|}{ Full light intensity (about $0.45 \mathrm{cal} \mathrm{cm}^{-2} \min -1$ ) } \\
\hline 1 & 79 & 3 & 72 \\
\hline 2 & 68 & 4 & 49 \\
\hline 5 & 54 & 7 & 68 \\
\hline $\begin{array}{l}6 \\
(304) *\end{array}$ & 46 & $\begin{array}{l}8 \\
(283)^{*}\end{array}$ & 19 \\
\hline \multicolumn{4}{|c|}{ 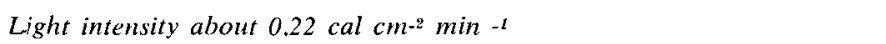 } \\
\hline 1 & 17 & 3 & 20 \\
\hline $\begin{array}{l}2 \\
(254) *\end{array}$ & 36 & $\begin{array}{l}4 \\
(259)^{*}\end{array}$ & 25 \\
\hline \multicolumn{4}{|c|}{ 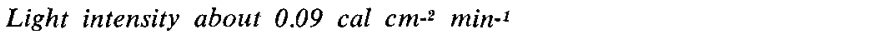 } \\
\hline 1 & 3 & 3 & 5 \\
\hline $\begin{array}{l}2 \\
(145) *\end{array}$ & 2 & $\begin{array}{l}4 \\
(156)^{*}\end{array}$ & $3 \%$ increase \\
\hline
\end{tabular}

* Figures in parentheses are average maximum rates of photosynthesis $\left(\mu \mathrm{g} \mathrm{CO}_{2} \mathrm{~cm}^{-2} \mathrm{~h}^{-1}\right)$ after 2 hours. 
contrary, the results with those of the experiments mentioned above, i.e. the order flag leaves in stage 11.1 (7.1) showed lower rates of photosynthesis (averages of 304 and $283 \mu \mathrm{g} \mathrm{CO}_{2}$ ) than the younger flag leaves in the flowering stage (averages of 360 and $373 \mu \mathrm{g} \mathrm{CO}_{2}$ ). Prolonged illumination at high light intensity also reduced the rate of photosynthesis of older flag leaves more than of young ones.

The variability in the remaining results was striking, both the reaction in the long peroid at full light intensity and that removal of the ears. At full light intensity the effect of the 16-hour period in stage $10.5 .3(6.3)$ was usually limited, except for plant 9 (34\%). Ear removal in this stage greatly affected 3 plants out of 6 , in the remaining plants it was small or negligible. In the older stage 11.1 (7.1) ear removal did not reduce photosynthesis more than the long duration at full light intensity of the control plants: plant 8 gave a deviating lower result.

At a light intensity of about $0.22 \mathrm{cal} \mathrm{cm}^{-2} \mathrm{~min}^{-1}$, control plants and plants without ears gave about the same reaction and a smaller reduction in $\mathrm{CO}_{2}$ uptake after 16 hours than at a higher intensity. This reduction was practically negligible at low light intensity of about $0.09 \mathrm{cal} \mathrm{cm}^{-2} \mathrm{~min}^{-1}$.

\section{Varietal differences in wheat and barley}

In recent years variation between and within species in photosynthetic efficiency has been widely demonstrated (Evans \& Dunstone, 1970; Apel \& Lehmann, 1969; Stoy, 1965; and others). Apel \& Lehmann (1969) found that out of 115 barley varieties of different geographical origins, studied under standard conditions, the photosynthetic rate of seven newly bred varieties ('Hochzuchtsorten') was near to the extreme positive value (200-220 $\mu \mathrm{g} \mathrm{CO}_{2} \mathrm{~cm}^{-2} \mathrm{~h}^{-1}$ ) determined by the variability distribution curve of the values of all the varieties, with a variability between genotypes of about 140 tot $230 \mu \mathrm{g}$ $\mathrm{CO}_{2} \mathrm{~cm}^{-2} \mathrm{~h}^{-1}$. Stoy (1965) measured the rates of photosynthesis of a limited number of wheat varieties of widely different origins. The results varied between genotypes from 285 to $367 \mu \mathrm{g} \mathrm{CO}_{2} \mathrm{~cm}^{-2} \mathrm{~h}^{-1}$, or a difference between highest and lowest mean values of $22 \%$ of the highest value.

Spring wheat varieties. During the last four years, a number of spring wheat varieties have been tested in experiments that are comparable because plants were grown under standard conditions (growth chamber at $15{ }^{\circ} \mathrm{C}$ constant, day-length $17 \mathrm{~h}$, light intensity ábout $0.1 \mathrm{cal} \mathrm{cm}^{-2} \mathrm{~min}^{-1}$, rate of photosynthesis light intensity $0.45 \mathrm{cal} \mathrm{cm}^{-2} \mathrm{~min}^{-1}$, leaf temperatures $24-26^{\circ} \mathrm{C}$ ).

The range of rates of photosynthesis measured showed a lowest mean value of $325 \mu \mathrm{g}$ $\mathrm{CO}_{2} \mathrm{~cm}^{-2} \mathrm{~h}^{-1}$ and a highest mean value of $414 \mu \mathrm{g}$; just as with the results of Stoy, there is a difference between the highest and lowest mean value of about $22 \%$ of the highest value.

The 18 varieties can be classified according to Table 8 . Although 18 is too small a number of varieties to prove that these results correspond with a normal variability distribution curve, as was shown more clearly by Apel \& Lehmann with the data from 115 barley varieties, we may assume that this is also so with these varieties. In contrast with their results, however, the rates of modern productive wheat varieties are also on the side of the frequency curve with the lower values. So the rates of photosynthesis are not directly related to grain yield, as is clearly indicated by the data of the four spring wheat varieties grown in the Netherlands, Orca, Jufy I, Gaby and Opal, grown on $57 \%, 34 \%, 6 \%$ and $2 \%$ of the total spring wheat acreage in 1970 , respectively. 
Table 8. Mean values of net rates of photosynthesis $\left(\mu \mathrm{g} \mathrm{CO}_{2} \mathrm{~cm}^{-2} \mathrm{~h}^{-1}\right)$ in 18 spring wheat varieties.

\begin{tabular}{lll}
\hline Mean values & Varieties & Origin \\
$320-340$ & Orca & Netherlands \\
$340-360$ & Lerma Rojo 64, Bajio 67 & Mexico \\
& Nepal 42 & Nepal \\
$360-380$ & Van Hoek, Artois $\times$ Mexico 43 sel. & Netherlands \\
& Ciano 67, Sonora 64* & Mexico \\
& Reliance, Thatcher & Canada \\
& Rex & France \\
& Jufy I & Belgium \\
& Ring & Sweden \\
$380-400$ & Opal* & Germany \\
& Gaby & Belgium \\
& Charter & Australia \\
& Mara & Italy \\
$400-420$ & Pilote $\times$ Mexico 63 sel. & Netherlands \\
& &
\end{tabular}

* Standard varieties used in each experiment for comparison.

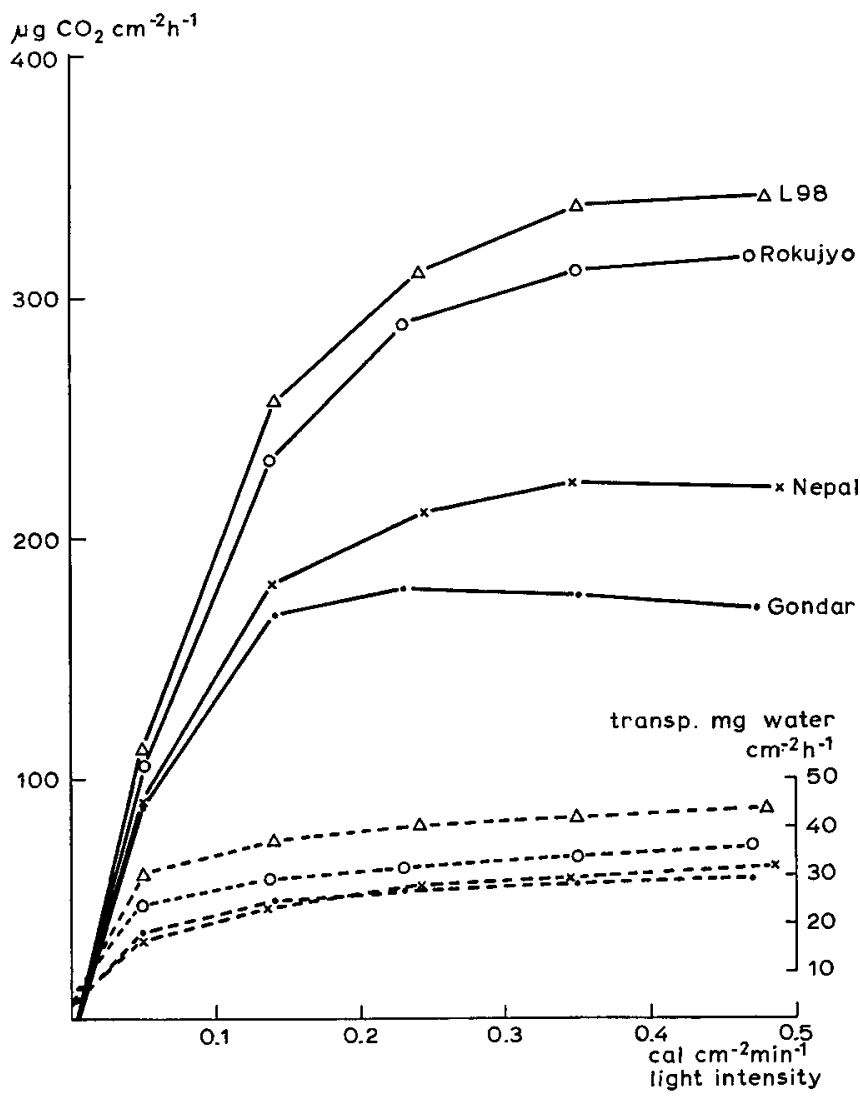

Fig. 1. Relationship between photosynthetic rate and light intensity in four barley varieties. 
Table 9. Mean values in net rates of photosynthesis $\left(\mu \mathrm{g} \mathrm{CO}_{2} \mathrm{~cm}^{-2} \mathrm{~h}^{-1}\right)$ of spring barley varieties.

\begin{tabular}{lll}
\hline Mean values & Varieties & Origin \\
$280-300$ & Piroline & Germany \\
& Ceres & France \\
$300-320$ & Union, Impala & Germany \\
& Quantum & Austria \\
& Rika & Sweden \\
& Rokujyo & Japan \\
& Brandon M75-754 & Canada \\
& L 92 & Ethiopia \\
$320-340$ & Zephyr & Netheriands \\
$340-360$ & L 98 & Ethiopia \\
$360-380$ & Sel. 62286-1 & Netherlands \\
& Goudgerst & Sweden \\
\hline
\end{tabular}

Spring barley varieties. In a series of 13 spring barley varieties, a difference between the highest and lowest mean values of rates of photosynthesis of about $22.5 \%$ of the highest value was found. The highest mean value was $366 \mu \mathrm{g} \mathrm{CO}_{2} \mathrm{~cm}^{-2} \mathrm{~h}^{-1}$ and the lowest 284. Apart from the 13 varieties, 4 others for unknown reasons reacted differently, in particular the varieties Nepal and Gondar (Fig. 1). 'Normal' curves are represented here by the varieties L 98 and Rokujyo; a still increasing rate of photosynthesis, even at the higher light intensities, almost reaches saturation near the highest intensity of about $0.45 \mathrm{cal} \mathrm{cm}^{-2} \mathrm{~min}^{-1}$. Most varieties with this 'normal' type of curve did not show much difference in transpiration rates, but here the diference between the two varieties was considerable. The other varieties Nepal and Gondar attained the highest rates at lower light intensities of about 0.35 and $0.23 \mathrm{cal} \mathrm{cm}^{-2} \mathrm{~min}^{-1}$, respectively, with still lower rates of transpiration than the above mentioned varieties.

The results of 13 varieties are given in Table 9. For these data the penultimate leaves were used, as the flag leaves were mostly too small for the assimilation chambers. The plants were raised in a growth chamber at $20^{\circ} \mathrm{C}$ and the results are given at the highest light intensity of about $0.45 \mathrm{cal} \mathrm{cm}^{-2} \mathrm{~min}^{-1}$ and in $\mu \mathrm{g} \mathrm{CO}_{2} \mathrm{~cm}^{-2} \mathbf{h}^{-1}$.

\section{Discussion}

As has been clearly shown, it is not easy to compare the rate of photosynthesis of different genotypes of wheat and barley. There are different factors that affect the results. Of these the effect of leaf rank, leaf age, nitrogen nutrition, temperature, length of illumination period and the possible demand for photosynthates by the developing ear have been studied. Only leaf rank does not seem tot have an effect, provided the successive leaves are of the same physiological age when compared for their photosynthetic ability. All the other factors, however, show a distinct effect (e.g. age, nitrogen nutrition, temperature and length of the illumination period) or an indistinct effect (e.g. presence or absence of a sink). As an example the data obtained on the rate of photosynthesis of the flag leaf of Sonora 64 are given, first the variation obtained under standard conditions and then the results obtained when the different factors were studied. 
The standard conditions are the following:

1. growing the plant material:

growth chamber conditions:

temperature: $15^{\circ} \mathrm{C}$ (wheat); $20^{\circ} \mathrm{C}$ (barley and some wheat experiments);

light source: 400 W HPL Mercury Vapour Lamps (Philips); glass-screen;

light intensity: $0.1 \mathrm{cal} \mathrm{cm}^{-2} \mathrm{~min}^{-1}$ at plant height;

relative humidity: $70-80 \%$;

nutrient solution: Hoagland $1 / 2$ strength $+\mathrm{A}+\mathrm{Z}$, renewed 3 times a week, 3 plants in 9-litre pots of solution on turntables;

2. photosynthesis chamber conditions:

leaf chambers: leaves attached perpendicular to light source

leaf temperature: $24-26^{\circ} \mathrm{C}$

light source: $400 \mathrm{~W}$ HPL mercury vapour lamps (Philips); water + glass screen;

light intensity: $0.45 \mathrm{cal} \mathrm{cm}^{-2} \mathrm{~min}^{-1}$;

$\mathrm{CO}_{2}$ concentration: $300 \mu \mathrm{g} / \mathrm{g}$.

Even when conditions in growing the plants and measuring the rate of photosynthesis were carried out with utmost accuracy the variation in the results have been considerable. This variation is remarkable, because usually the values do not deviate very much from the mean value, but occasionally in some experiments rather large deviations occur for some completely obscure reason. When varieties were not pure, only seed from selected plants was used. D.N. Moss found this variability within varieties to be nongenetic, since he had the same problems with leaves from different tillers of the same plant (pers. commun.). Because of this variability it is usually impossible to obtain good results when only a few plants are used. This makes the method unsuitable for selection in a large number of varieties or selections.

Differences among genotypes could be established. For spring wheat as well as for spring barley differences of about $22 \%$ were found, holding only for a limited number of varieties, although from very different origin. These differences in rates of photosynthesis were not related to grain yield. The highest rates of photosynthesis were measured in leaves that were just full-grown. With the ageing of leaves the rates decreased gradually. However, this decrease was not so great that differences of a few days, which are unavoidable in comparing varieties, will be very important.

Apel \& Lehmann (1969) measured the rates of photosynthesis of the 2nd, 4th, 5th, 6th, and 7 th leaves of two barley varieties, at the moment that these leaves had attained their ultimate area. They found that in these different stages of the ontogenesis of the plant the rates of photosynthesis remained he same. With the above-mentioned results of the last three leaves of the plants (Tables 1,2 and 3), this means that all the leaves of a wheat and a barley plant most probably have the same photosynthetic efficiency, provided they are in comparable stages of growth.

Osman \& Milthorpe (1971) found the capacity of wheat leaves for photosynthesis was greatest at the time when the leaf attained its ultimate area, both younger and older leaves being less efficient.

Relations between nitrogen content of the leaves and rates of photosynthesis have recently been demonstrated in several experiments with different crops. In sugar-beet, Nevins \& Loomis (1970) found that growing plants for 14 days without nitrogen reduced the rate of photosynthesis as much as $40 \%$. The effects were reversible, however and activity could be restored to the normal rate within 4 days by adding nitrate nitrogen to the deficient nitrogen solution. From experiments with wheat, Osman \& Milthorpe (1971) report that the rate of photosynthesis was closely correlated with 
the concentration of nitrogen, and Khan \& Tsunoda (1970) that this rate was positively correlated with nitrogen content per leaf area. Sasahara (1971) found in Brassica species a positive correlation between photosynthetic activity per leaf area and nitrogen content of the total leaf area. In this study attention was paid to the effect of the protein content of the leaves on the rates of photosynthesis (Tables 4 and 5). A correlation between these two factors could be established, but only for leaves of the same age.

Several results in the literature indicate that the rate of photosynthesis can vary in response to changes in the demand for assimilates, for instance in wheat (Evans \& Rawson, 1970). Dornhoff \& Shilles (1970) stated that the increase in net photosynthesis of soya bean leaves was the result of (a) decreased $\mathrm{CO}_{2}$ diffusion resistance within the leaf or (b) increased demand for photosynthates for seed formation. Net photosynthesis of most varieties began to increase at the approximate beginning of seed filling. King et al. (1967) found with wheat that on removing the ear, net photosynthesis by the flag leaves was reduced by about $50 \%$ within 3-15 hours. From their results they suggested that photosynthesis by the flag leaf is regulated directly by the demand for assimilates from this leaf. These results do not conform with those from the first experiments (Tables 1, 2 and 3) and from Osman \& Milthorpe (1971), indicating that the photosynthetic capacity of the leaves decreases after the period that the leaves have attained their ultimate area. In two experiments, designed to investigate whether there is a direct regulation of photosynthesis of the leaves by the demand for assimilates from the leaves, two groups of plants were compared: normal intact plants and plants of which the ears and part of the peduncles were removed (Tables 6 and 7). In only one case (Table 6, plants 5 and 6 versus plants 7 and 8 ) did the removal of the ears result in a considerable decrease in rates of photosynthesis, while in the intact plants there was hardly any change in these rates. In the remaining cases there was sometimes hardly any difference between both groups of plants; in some cases the reaction was quite contrary to that of the pairs of plants mentioned above, or the two plants of a pair reacted quite differently. Again here a variability in results, that makes many replicates absolutely necessary.

\section{References}

Apel, P. \& Chr. O. Lehmann, 1969. Variabilität und Sortenspezifität der Photosyntheserate bei Sommergerste. Photosynthetica 3: 255-262.

Dornhoff, G. M. \& R. M. Shibles, 1970. Varietal differences in net photosynthesis of soybean leaves. Crop. Sci. 10: 42-45.

Evans, L. T. \& R. L. Dunstone, 1970. Some physiological aspects of evolution in wheat.Aust. J. biol. Sci. 23: 725-741.

Evans, L. T. \& H. M. Rawson, 1970. Photosynthesis and respiration by the flag leaf and components of the ear during grain development in wheat. Aust. J. biol. Sci. 23: 245-254.

Khan, M. A. \& S. Tsunoda, 1970. Leaf photosynthesis and transpiration under different levels of air flow rate and light intensity in cultivated wheat species and its wild relatives. Jap. J. Breed. 20: 305-314.

King, R. W. et al., 1967. Effect of assimilate utilization on photosynthetic rate in wheat. Planta 77: 261-276.

Louwerse, W. \& J. L. P. van Oorschot, 1969. An assembly for routine measurements of photosynthesis, respiration and transpiration of intact plants under controlled conditions. Photosynthetica 3: $305-315$.

Lupton, F. G. H., 1961. Varietal differences in some physiological characters of wheat. Ann. appl. Biol. 49: $557-560$.

Nevins, D. J. \& R. S. Loomis, 1970. Nitrogen nutrition and photosynthesis in sugar beet. Crop Sci. 10: $21-25$. 
Osman, A. M. \& F. L. Milthorpe, 1971. Photosynthesis of wheat leaves in relation to age, illuminance and nutrient supply II. Results. Photosynthetica 5: 61-70.

Sasahara, T., 1971. Total cell surface area in the palisade parenchyma and total cell surface area: Total nitrogen content ratio in relation to photosynthetic activity in Brassica. Jap. J. Breed. 21: 61-68.

Stoy, V., 1965. Photosynthesis, respiration and carbohydrate accumulation in spring wheat in relation to yield. Physiologia Pl., Suppl. IV, 125 pp. Lund. 